\title{
I-MOVE multicentre case-control study 2010/11 to 2014/15: Is there within-season waning of influenza type/subtype vaccine effectiveness with increasing time since vaccination?
}

E Kissling ${ }^{1}$, B Nunes ${ }^{2}$, C Robertson ${ }^{345}$, M Valenciano ${ }^{1}$, A Reuss ${ }^{6}$, A Larrauri ${ }^{78}$, JM Cohen 9 , B Oroszi ${ }^{10}$, C Rizzo ${ }^{11}$, A Machado

${ }^{2}$, D Pitigoi ${ }^{12}{ }^{13}$, L Domegan ${ }^{14}$, I Paradowska-Stankiewicz ${ }^{15}$, U Buchholz ${ }^{6}$, A Gherasim ${ }^{7}$, I Daviaud ${ }^{9}$, JK Horváth ${ }^{10}$, A Bella ${ }^{11}$, E Lupulescu ${ }^{12}$, J O'Donnell ${ }^{14}$, M Korczyńska ${ }^{15}$, A Moren ${ }^{1}$, I-MOVE case-control study team ${ }^{16}$

1. EpiConcept, Paris, France

2. Instituto Nacional de Saúde Dr Ricardo Jorge, Lisbon, Portugal

3. Health Protection Scotland, Glasgow, United Kingdom

4. University of Strathclyde, Glasgow, United Kingdom

5. International Prevention Research Institute, Lyon, France

6. Department for Infectious Disease Epidemiology, Robert Koch Institute, Berlin, Germany

7. National Centre for Epidemiology, Instituto de Salud Carlos III, Madrid, Spain

8. Cyber, Epidemiología y Salud Pública (CIBERESP)

9. GROG/Open Rome, Paris, France

10. Office of the Chief Medical Officer, Budapest, Hungary

11. Istituto Superiore di Sanità, Rome, Italy

12. Cantacuzino Institute, National Institute of Research - Development for Microbiology and Immunology, Bucharest, Romania

13. Universitatea de Medicina si Farmacie Carol Davila, Bucharest, Romania

14. Health Protection Surveillance Centre, Dublin, Ireland

15. National Institute of Public Health-National Institute of Hygiene, Warsaw, Poland

16. Authors included in the I-MOVE multicentre case-control team (in addition to those already listed) are listed at the end of the article

Correspondence: Esther Kissling (e.kissling@epiconcept.fr)

Kissling E, Nunes B, Robertson C, Valenciano M, Reuss A, Larrauri A, Cohen JM, Oroszi B, Rizzo C, Machado A, Pitigoi D, Domegan L, Paradowska-Stankiewicz I, Buchholz U, Gherasim A, Daviaud I, Horváth JK, Bella A, Lupulescu E, O’Donnell J, Korczyńska M, Moren A, I-MOVE case-control study team. I-MOVE multicentre case-control study $2010 / 11$ to $2014 / 15$ : Is there within-season waning of influenza type/subtype vaccine effectiveness with increasing time since vaccination? Euro Surveill. 2016;21(16): pii=30201. DOI: http://dx.doi.org/10.2807/1560-7917.ES.2016.21.16.30201

Since the 2008/9 influenza season, the I-MOVE multicentre case-control study measures influenza vaccine effectiveness (VE) against medically-attended influenza-like-illness (ILI) laboratory confirmed as influenza. In 2011/12, European studies reported a decline in $V E$ against influenza $A\left(\mathrm{H}_{3} \mathrm{~N}_{2}\right)$ within the season. Using combined I-MOVE data from 2010/11 to $2014 / 15$ we studied the effects of time since vaccination on influenza type/subtype-specific VE. We modelled influenza type/subtype-specific VE by time since vaccination using a restricted cubic spline, controlling for potential confounders (age, sex, time of onset, chronic conditions). Over 10,000 ILI cases were included in each analysis of influenza $A\left(\mathrm{H}_{3} \mathrm{~N}_{2}\right)$, $A\left(H_{1} N_{1}\right) p d m o 9$ and $B$; with 4,759, 3,152 and 3,617 influenza positive cases respectively. VE against influenza $\mathrm{A}\left(\mathrm{H}_{3} \mathrm{~N}_{2}\right)$ reached $50.6 \%(95 \% \mathrm{Cl}: 30.0-65.1) 38$ days after vaccination, declined to $\%$ (95\% Cl: -18.1-15.2) from 111 days onwards. At day $54 \mathrm{VE}$ against influenza $\mathrm{A}\left(\mathrm{H}_{1} \mathrm{~N}_{1}\right)$ pdmo9 reached $55.3 \%$ (95\% Cl: $\left.37.9-67.9\right)$ and remained between this value and $50.3 \%(95 \% \mathrm{Cl}$ : 34.8-62.1) until season end. VE against influenza $B$ declined from $70.7 \%$ ( $95 \% \mathrm{Cl}: 51.3-82.4) 44$ days after vaccination to $21.4 \%(95 \% \mathrm{Cl}:-57.4-60.8)$ at season end. To assess if vaccination campaign strategies need revising more evidence on VE by time since vaccination is urgently needed.

\section{Introduction}

Influenza vaccination is currently the best measure available to prevent seasonal influenza infection. In most European countries one dose (or two doses for children) of seasonal vaccine is recommended from late September/October to November/December for target groups for vaccination, which may include the elderly (either $\geq 55, \geq 60$ or $\geq 65$ years of age), clinical risk groups, pregnant women, healthcare workers, other occupational groups and other groups depending on country [1]. In Europe, influenza seasons can last until mid-May [2], and it is expected that vaccination confers protection to the individual for the duration of the season. In thirteen of fifteen reviewed studies on the length of vaccine-induced protection among the elderly, using anti-haemagglutination antibody titres as a proxy for seroprotection levels, seroprotection rates lasted at least 4 months after vaccination [3]. 


\section{FIGURE 1}

Onset of influenza-like illness (ILI) among (A) influenza $\mathrm{A}(\mathrm{H} 3 \mathrm{~N} 2),(\mathrm{B}) \mathrm{A}(\mathrm{H} 1 \mathrm{~N} 1) \mathrm{pdm} 09$ and $(\mathrm{C}) \mathrm{B}$ cases, by season and pooled, and dates of vaccination ${ }^{\mathrm{a}}$ of ILI patients, by ISO week, I-MOVE multicentre case-control study, influenza seasons 2010/11-2014/15

A. Influenza A ( $\left.\mathrm{H}_{3} \mathrm{~N}_{2}\right)$

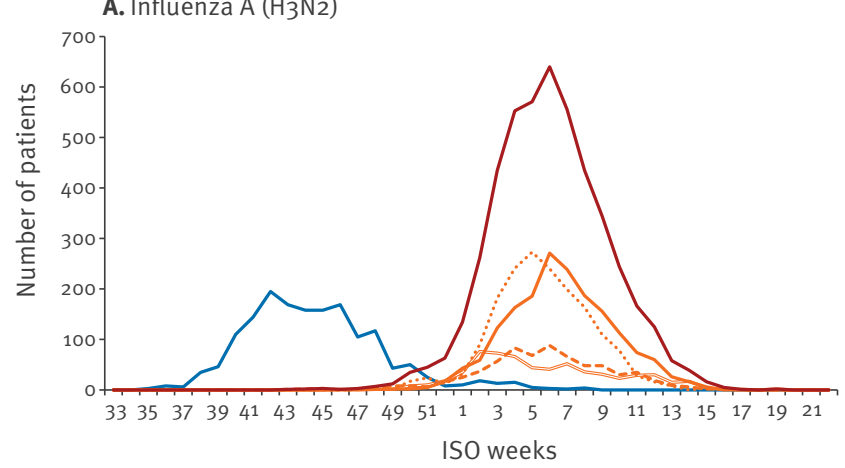

— ILI patients vaccinated (all seasons; $\mathrm{N}=1,619$ )

- $A\left(\mathrm{H}_{3} \mathrm{~N}_{2}\right)$ cases 2011-12 $(\mathrm{N}=1,751)$

-.- $A\left(\mathrm{H}_{3} \mathrm{~N}_{2}\right)$ cases 2012-13 $(\mathrm{N}=672)$

- $\mathrm{A}\left(\mathrm{H}_{3} \mathrm{~N}_{2}\right)$ cases 2013-14 $(\mathrm{N}=614)$

..... $\mathrm{A}\left(\mathrm{H}_{3} \mathrm{~N}_{2}\right)$ cases $2014-15(\mathrm{~N}=1,722)$

- $A\left(\mathrm{H}_{3} \mathrm{~N}_{2}\right)$ cases all seasons $(\mathrm{N}=4,759)$

B. Influenza A ( $\left.\mathrm{H}_{1} \mathrm{~N}_{1}\right)$

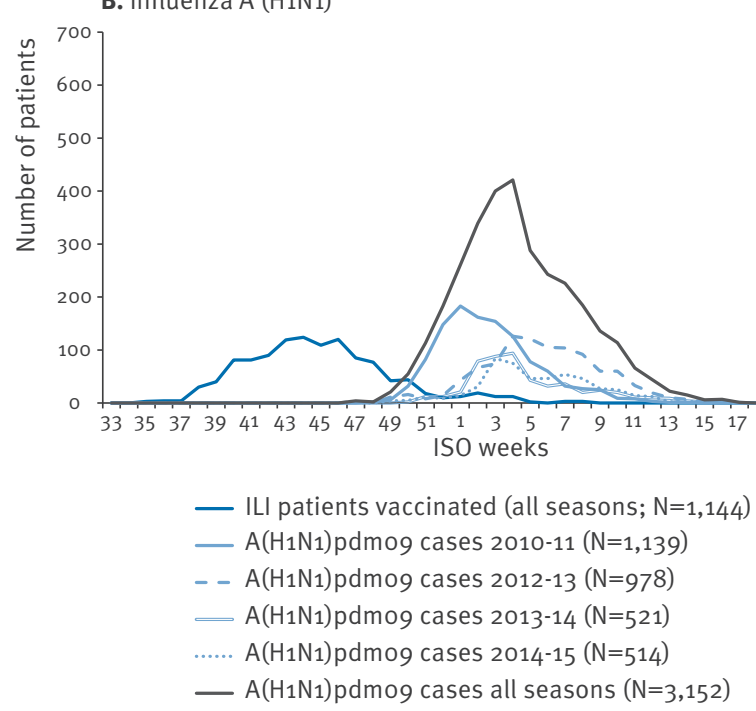

C. Influenza B

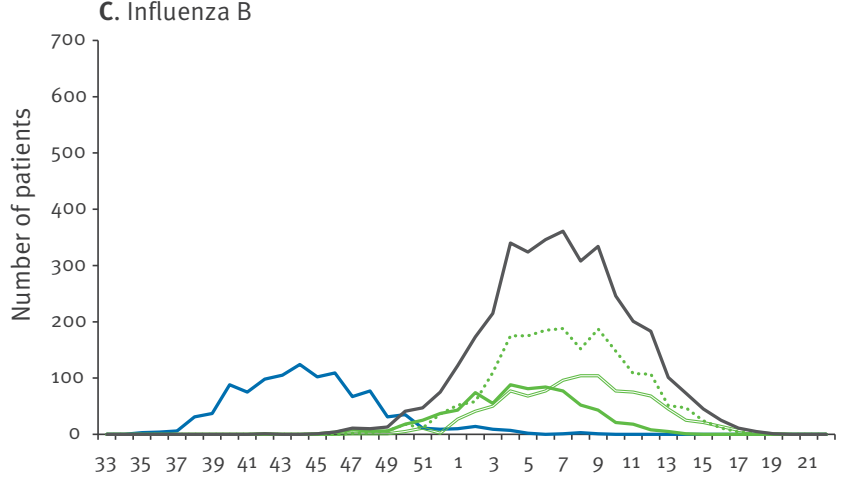

ISO weeks

— ILI patients vaccinated (all seasons; $N=1,059$ )

- B cases 2010-11 $(\mathrm{N}=755)$

..... B cases 2012-13 $(\mathrm{N}=1,860)$

B cases $2014-15(\mathrm{~N}=1,002)$

- $B$ cases all seasons $(N=3,617)$

ILI: influenza-like illness; ISO: International Organisation for Standardisation a Patients vaccinated include those vaccinated $<15$ days before symptom onset.
However, in the 2011/12 influenza season various studies in Europe reported a decrease in influenza vaccine effectiveness (VE) against $\mathrm{A}\left(\mathrm{H}_{3} \mathrm{~N}_{2}\right)$ over time within the season [4-7]. In the United States (US), a decrease in VE against $\mathrm{A}\left(\mathrm{H}_{3} \mathrm{~N}_{2}\right)$ with time since vaccination was also observed in the 2007/08 influenza season [8].

The observed decrease of VE over time may be explained by viral change (notably antigenic drift) occurring in the season. Drift in $B$ viruses may be slower than in $A$ viruses [9], and $A\left(H_{3} N_{2}\right)$ viruses have a higher rate of nucleotide substitutions than $A\left(\mathrm{H}_{1} \mathrm{~N}_{1}\right)$ pdmog viruses [10].

The decrease of VE over time can also be explained by a waning of the immunity conferred by the vaccine independently from viral changes. If vaccine-induced protection wanes during the season, then depending on the start and duration of the influenza season, the decline of VE may cause increases in overall incidence, outbreaks, particularly in residential care facilities, as well as hospitalisations and deaths. Changes to vaccination strategies i.e. timing and/or boosters, may be needed.

As anti-haemagglutination antibody titres are not well defined as a correlate of protection [11,12], vaccine efficacy, as measured in trials, or VE measured in observational studies may be one way to measure vaccine-induced protection. These studies require a large sample size to model VE by time since vaccination and currently, most of the seasonal observational studies lack the precision required to provide evidence for waning effectiveness.

In this study we pooled data across five post-pandemic seasons, namely $2010 / 11$ to $2014 / 15$, from the I-MOVE (influenza-monitoring vaccine effectiveness) multicentre case-control studies $[2,4,13,14]$, to obtain a larger sample size to study the effects of time since vaccination on influenza type/subtype-specific VE. We measured influenza type/subtype-specific VE by time since vaccination for the overall season, but also in the early phase of the influenza season. Under the hypothesis that virological changes are fewer in the early season, waning of the vaccine effect should be present regardless of phase within the season.

\section{Methods}

The I-MOVE multicentre case-control study methods are described in detail elsewhere $[15,16]$, and are based on the European Centre for Disease Prevention and Control (ECDC) generic influenza VE case-control study protocol [17].

Briefly, several countries (between six and eight depending on the season, during the 2010/11 to 2014/15 study period) carried out a test-negative casecontrol study each season to measure influenza VE and sent their data to a central hub for pooled analysis. Participating practitioners interviewed and collected 


\section{FIGURE 2}

Pooled-season adjusted vaccine effectiveness against influenza $\mathrm{A}(\mathrm{H} 3 \mathrm{~N} 2)$ by time since vaccination (days), I-MOVE multicentre case-control study, influenza seasons 2011/12-2014/15
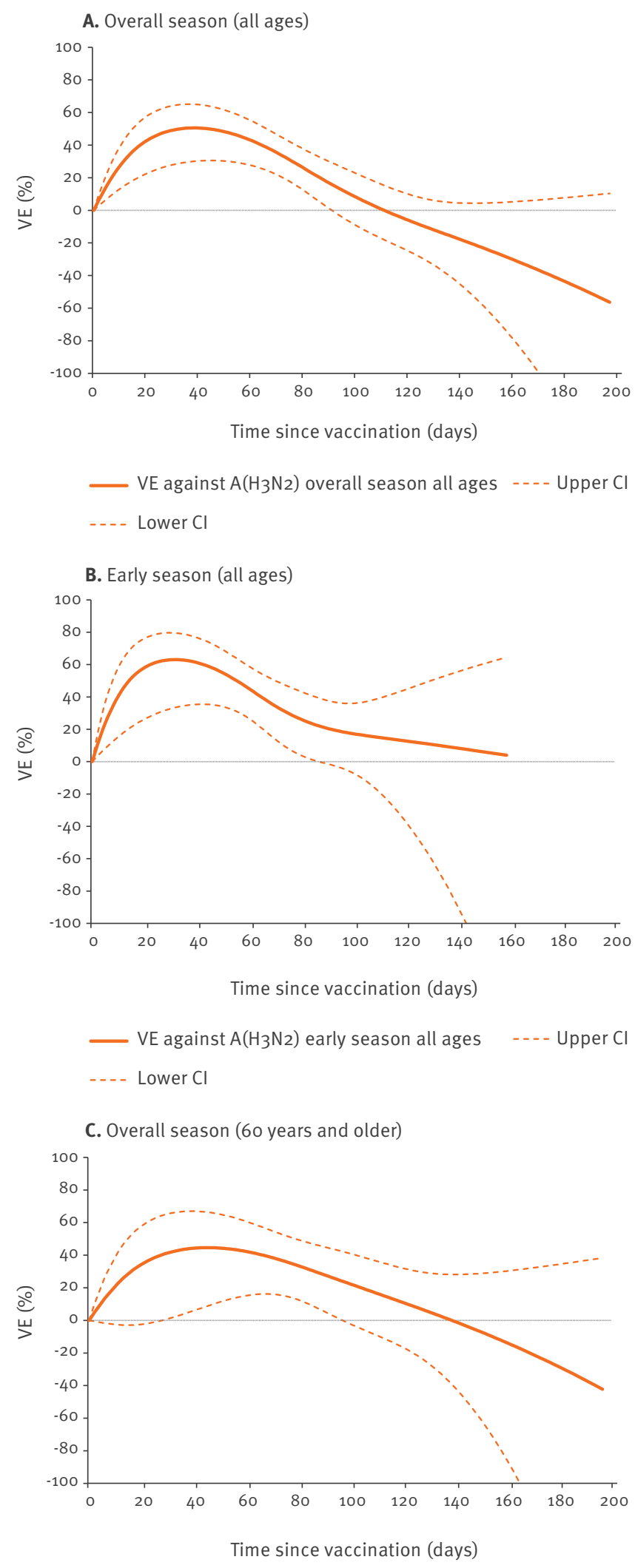

_ VE against $\mathrm{A}\left(\mathrm{H}_{3} \mathrm{~N}_{2}\right)$ overall season 60 years and older
- - - Upper $\mathrm{Cl}$
-. - - Lower $\mathrm{Cl}$

$\mathrm{Cl}$ : confidence intervals; VE: vaccine effectiveness. naso-pharyngeal specimens from a systematic sample of or all patients, depending on age group, consulting for influenza like illness (ILI). Practitioners obtained clinical and epidemiological information, including vaccination status, date of vaccination and vaccine product. Cases were patients whose swabs tested positive for influenza virus using real-time reverse-transcription PCR (RT-PCR), controls were patients whose swabs tested negative for influenza virus using RT-PCR.

In the pooled analysis we included patients who consulted their practitioner more than 14 days after the start of national or regional seasonal influenza vaccination campaign, who met the criteria for the European Union ILI case definition [18], who were swabbed less than eight days after symptom onset and who did not receive antivirals before swabbing.

For each study site each influenza type/subtype- and season-specific study period began at the week of onset of the first influenza case and ended at the week of onset of the last influenza case after which there were at least two consecutive weeks with no further influenza-positive cases of that influenza type/ subtype.

We defined patients as vaccinated if they had received at least one dose of influenza vaccine more than 14 days before symptom onset. Patients receiving a dose of vaccine $<15$ days before symptom onset and receiving no dose of vaccine were defined as unvaccinated.

For each influenza season and for each influenza type/ subtype-specific analysis we partitioned the influenza season into two and created an early and late influenza phase. This was based on a mid-season date with an equal number of type/subtype-specific cases by dates of onset on either side.

For each season, we used logistic regression to compute the odds ratio (OR) of being vaccinated in cases and controls. We estimated the type/subtype-adjusted influenza VE as (1 minus the OR)*10o. Study site was modelled as a fixed effect and always included in the analysis model. We used Cochran's Q-test and the $I^{2}$ index to test for heterogeneity between seasons [19]. We pooled individual data across the seasons, always including study site and season as a fixed effect in the crude or adjusted analysis model. We measured VE where sample size was high enough (number of model parameters $<10-15 \%$ of number of cases) carrying out a complete analysis excluding patients with missing values for any of the variables in the model measuring VE. We included age, sex, presence of a risk factor for complications, including chronic conditions, pregnancy and obesity where available, and week of symptom onset as covariates in the models. Age was modelled using a restricted cubic spline, with four or three knots depending on sample size with knots specified according to Harrell [20]. 


\section{FIGURE 3}

Pooled season adjusted vaccine effectiveness against influenza $\mathrm{A}(\mathrm{H} 1 \mathrm{~N} 1) \mathrm{pdm} 09$ by time since vaccination (days), I-MOVE multicentre case-control study, influenza seasons 2010/11 and 2012/13-2014/15

A. Overall season (all ages)

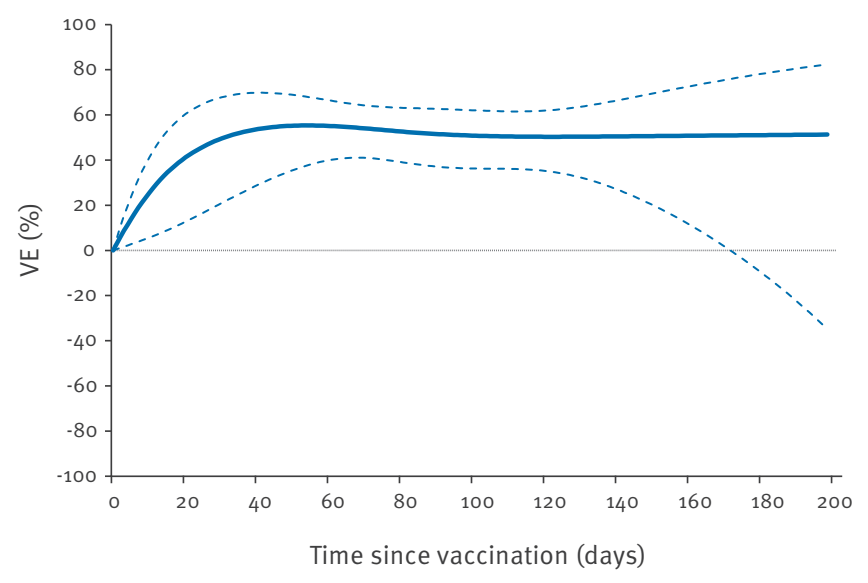

_ VE against $A\left(\mathrm{H}_{1} \mathrm{~N}_{1}\right)$ overall season all ages

-.- - Upper Cl

-..- Lower Cl

B. Early season (all ages)

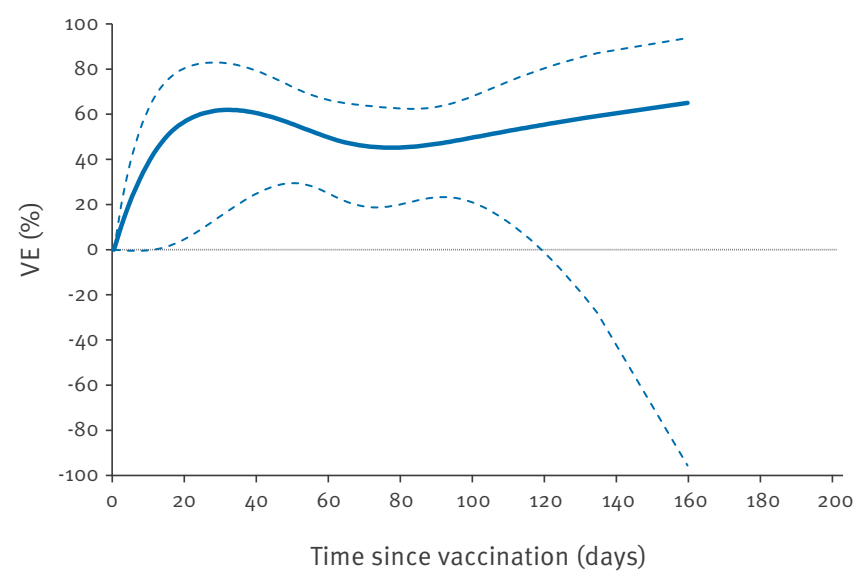

_ VE against $\mathrm{A}\left(\mathrm{H}_{1} \mathrm{~N}_{1}\right)$ early season all ages

-.-. Upper Cl

-... Lower $\mathrm{Cl}$

$\mathrm{Cl}$ : confidence interval; VE: vaccine effectiveness.

We measured influenza type/subtype-specific VE for the whole influenza season, for the early and late influenza phase, and for all ages and among those aged 60 years and older.

We coded time since vaccination as date of onset of symptoms minus date of vaccination with persons not receiving the vaccine coded as 'o days' [21]. We modelled time since vaccination using a cubic spline, tail-restricted at the upper end, with four knots, two a priori at zero and 15 days and then at the 40th and 9oth centile. Those vaccinated less than 15 days before symptom onset were modelled as well and were considered vaccinated for this time since vaccination analysis. We included season, study site and the same covariates as above in the analysis. We measured type/ subtype-specific VE by time since vaccination for the whole influenza season and by early influenza phase among all ages. Among those aged 60 years and older we measured type/subtype-specific VE by time since vaccination for the whole influenza season. We did not attempt the modelling where the number of vaccinated cases was lower than 50.

In a sensitivity analysis we assessed the shape, the coefficients and the model fit using the Aikaike Information Criterion (AIC) and Bayesian Information Criterion (BIC) of the model, with varying number and placement of knots. We further evaluated the inclusion of onset weeks in case of collinearity between the two time variables: time since vaccination and onset week. Where sample size was sufficiently large, we also modelled VE by time since vaccination for each individual season and for each influenza type/subtype.

\section{Results}

Among the five seasons studied (2010/11 to 2014/15), we included four seasons with influenza $A\left(\mathrm{H}_{3} \mathrm{~N}_{2}\right)$, four seasons with influenza $A\left(\mathrm{H}_{1} \mathrm{~N}_{1}\right)$ pdmog and three seasons with influenza $B$ in the analysis, as these were the seasons with sufficient circulation of these influenza types/subtypes to carry out our analyses. Influenza seasons varied in terms of start, intensity and duration by influenza type/subtype (Figure 1). Seventy-nine percent of vaccinations were carried out before the first influenza positive case in the study in each country. This varied by $40-100 \%$ by country.

Among the 2,224 vaccinated patients (9.6\%), the name of the vaccine product was available for 1,909 (85.8\%). All vaccines were inactivated, with $52.4 \%$ $(n=1,000)$ of patients vaccinated with egg-derived split virion, $24.8 \%(n=474)$ with egg-derived subunit, $21.1 \%$ $(n=403)$ with adjuvanted and $1.7 \%(n=32)$ with cellderived subunit vaccine. Patients vaccinated within 1.5 months (45 days) after begin of each season-specific vaccination campaign by country were more likely to be older than those vaccinated later: median age 64 (interquartile range (IQR) 46-73), compared with 53 (IQR 13-69), respectively. They were also more likely to have a chronic condition: $61.8 \%$ compared with $52.2 \%$.

\section{Influenza $\mathrm{A}(\mathrm{H} 3 \mathrm{~N} 2)$}

We included 13,738 ILI cases in the pooled-season complete case analysis for influenza $A\left(\mathrm{H}_{3} \mathrm{~N}_{2}\right)$, of which 4,759 (34.6\%) were $\mathrm{A}\left(\mathrm{H}_{3} \mathrm{~N}_{2}\right)$ influenza positive cases. Among those aged 60 and over we included 1,775 ILI cases, 672 (37.9\%) of those were influenza $A\left(\mathrm{H}_{3} \mathrm{~N}_{2}\right)$ positive. The percentage of records dropped from the complete case analysis among all ages due to missing data was $5.5 \%$. 


\section{FIGURE 4}

Pooled season adjusted vaccine effectiveness against influenza B by time since vaccination (days), I-MOVE multicentre case-control study, influenza seasons 2010/11, 2012/13 and 2014/15
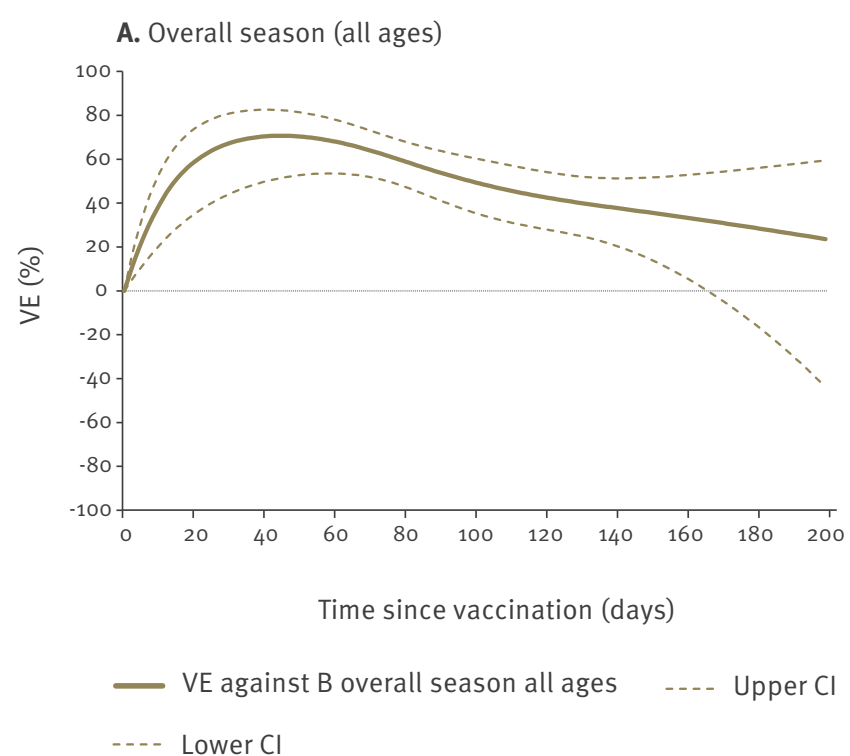

B. Early season (all ages)

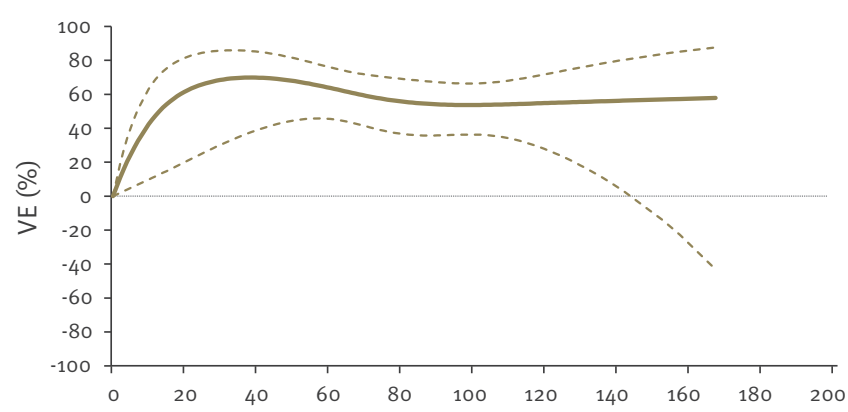

Time since vaccination (days)

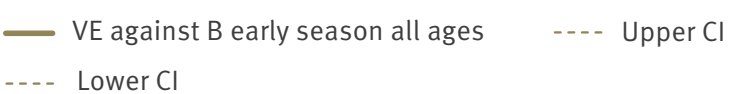

C. Overall season (6o years and older)

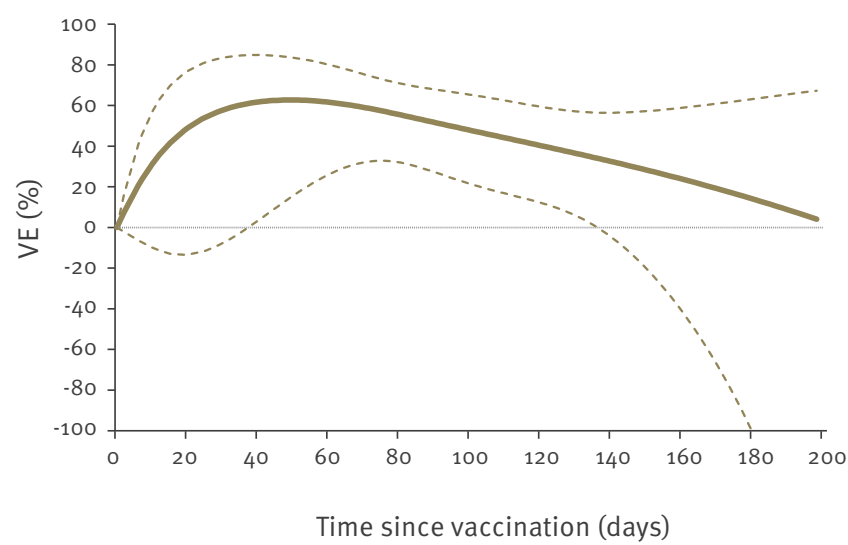

_ VE against B overall season --- Upper Cl 60 years and older

-... Lower Cl

$\mathrm{Cl}$ : confidence intervals; VE: vaccine effectiveness.
The VE by season against influenza $\mathrm{A}\left(\mathrm{H}_{3} \mathrm{~N}_{2}\right)$ ranged between $5.9 \%$ and $42.2 \%$. The pooled-season adjusted VE (psAVE) was $15.0 \%$, with an $\mathrm{I}^{2}$ index of $27.3 \%$. Among those aged 60 years and older, the psAVE was $23.0 \%$ with an $\mathrm{I}^{2}$ of $0.0 \%$ (Table 1 ).

Mid-season dates partitioning the early and late influenza phase varied by 13 days between seasons (30 January to 12 February). Among all ages the psAVE was $32.1 \%$ in the early phase and $-2.8 \%$ in the late phase (Table 2). Among those aged 60 years and older the psAVE was $36.8 \%$ in the early phase and $9.2 \%$ in the late phase.

When modelling the psAVE by days since vaccination against influenza $A\left(\mathrm{H}_{3} \mathrm{~N}_{2}\right)$, we see an initial increase to a peak, followed by a steady decline. Among all ages the psAVE against $\mathrm{A}\left(\mathrm{H}_{3} \mathrm{~N}_{2}\right)$ by days since vaccination initially increased to $50.6 \%$ at 38 days since vaccination (Figure 2). It then declined to $0 \%$ at 111 days since vaccination, continually declining thereafter.

In the early influenza phase, the psAVE showed a similar pattern to the overall phase, with a peak of $63.1 \%$ at day 32. The psAVE then declined to $4.0 \%$ at 159 days. No patient was vaccinated more than 159 days before symptom onset in the early phase.

Among those aged 60 years and older the psAVE increased initially to $44.6 \%$ at day 45 . It then declined to $0 \%$ at day 140.

\section{Influenza $\mathrm{A}(\mathrm{H} 1 \mathrm{~N} 1)$ pdm09}

We included 11,385 ILI cases in the pooled-season complete case analysis against influenza $A\left(\mathrm{H}_{1} \mathrm{~N}_{1}\right)$ pdmog, of which 3,152 (27.7\%) tested influenza $A\left(\mathrm{H}_{1} \mathrm{~N}_{1}\right)$ pdmo9 positive. Among those aged 60 and over we included 1,228 ILI cases with 201 (16.4\%) A(H1N1)pdmo9-positive cases. Among all ages for the complete case analysis, we dropped $5.9 \%$ of records due to missing data.

The VE estimates by season were between $47.5 \%$ and $53.8 \%$ against $\mathrm{A}\left(\mathrm{H}_{1} \mathrm{~N}_{1}\right)$ pdmog resulting in a psAVE of $52.2 \%$. There was no statistical heterogeneity between season-specific VE estimates ( $I^{2}$ index $\left.0.0 \%\right)$. Among those aged 60 years and older, the psAVE was $54.0 \%$ with an $\mathrm{I}^{2}$ of $39.4 \%$ (Table 1 ).

Mid-season dates partitioning the early and late influenza phase varied by 20 days (14 January to 3 February). The psAVE against influenza $A\left(\mathrm{H}_{1} \mathrm{~N}_{1}\right)$ pdmog among all ages for the pooled early phase was $50.1 \%$ and $52.9 \%$ for the late phase (Table 2). Crude pooled-season VE against $\mathrm{A}\left(\mathrm{H}_{1} \mathrm{~N}_{1}\right)$ pdmog among those aged 60 and older in the pooled early phase was $44.7 \%$ and the AVE was $61.2 \%$ in the late phase, adjusted by month of onset of symptoms.

Modelling psAVE against influenza $\mathrm{A}\left(\mathrm{H}_{1} \mathrm{~N}_{1}\right)$ pdmog by days since vaccination did not suggest any decline in psAVE within the season. Among all ages the psAVE 


\section{FIGURE 5}

Adjusted vaccine effectiveness against influenza $\mathrm{A}(\mathrm{H} 3 \mathrm{~N} 2)$, all ages, by season, I-MOVE influenza seasons (A)

2011/12, (B) 2013/14, (C) 2014/15
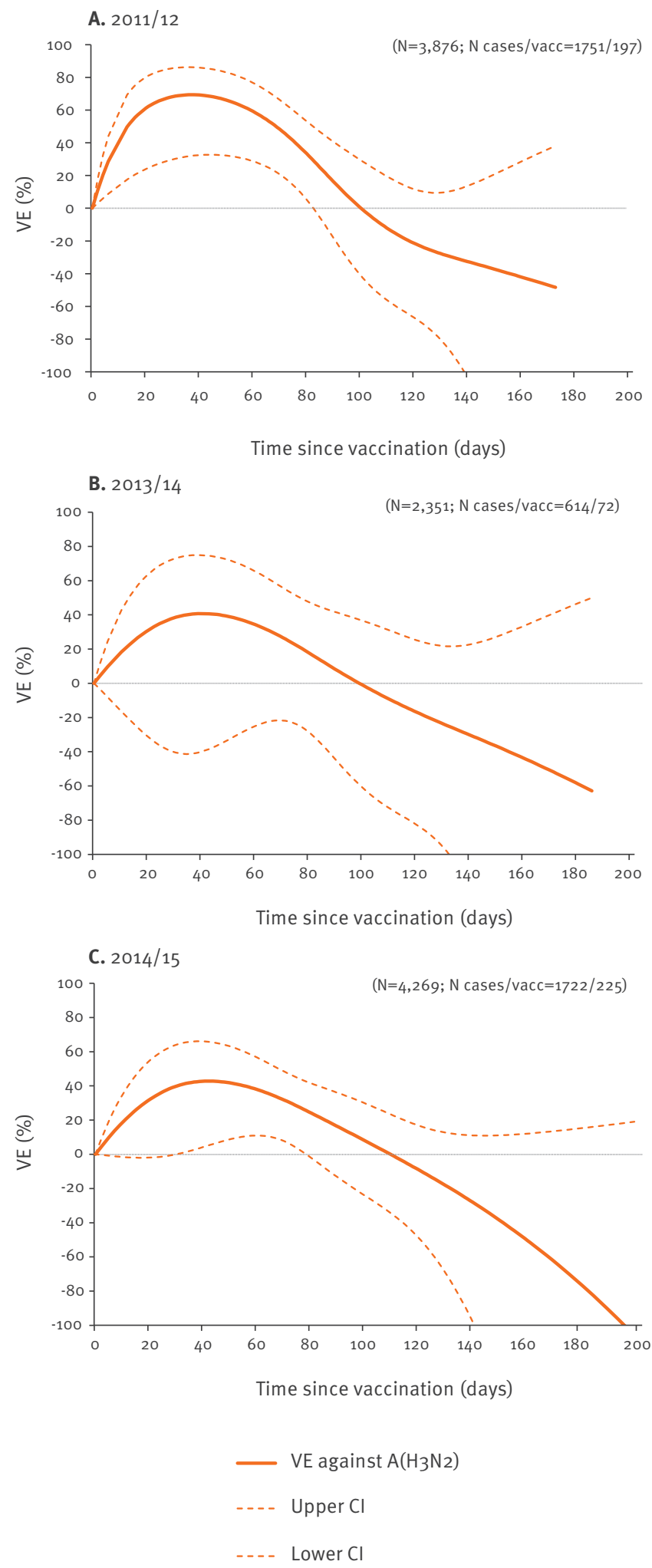

$\mathrm{Cl}$ : confidence intervals; VE: vaccine effectiveness. initially increased to $55.3 \%$ at day 54 (Figure 3). The psAVE then remained between $50.0 \%$ and $55.3 \%$ between 31 and 197 days since vaccination. No patients were vaccinated more than 197 days before symptom onset.

In the early influenza phase, the psAVE against influenza $A\left(\mathrm{H}_{1} \mathrm{~N}_{1}\right)$ pdmog showed a similar pattern to the overall phase initially, reaching $61.9 \%$ at day 32 . After that, the psAVE was variable, but never dipped below $45.2 \%$ (day 77). Sample size was too small to calculate the psAVE by time since vaccination among those aged 60 and older.

\section{Influenza B}

We included $10,900 \mathrm{ILI}$ cases in the pooled-season complete case analysis, of which 3,617 (33.2\%) were influenza B-positive. Among those aged 60 and over we included 1,274 ILI cases, among which 309 (24.3\%) were influenza B-positive. For the complete case analysis among all ages, we dropped $5.3 \%$ of records due to missing data.

The season-specific VE against influenza $B$ ranged from $47.6 \%$ to $55.0 \%$, with a psAVE of $50.7 \%$. There was no statistical heterogeneity between season-specific VE estimates for influenza B ( $\mathrm{I}^{2}$ index $\left.0.0 \%\right)$. Among those aged 60 years and older, the psAVE was $45.7 \%$ against influenza B with an $\mathrm{I}^{2}$ of $0.0 \%$ (Table 1 ).

Mid-season dates partitioning the early and late influenza phase varied by 19 days (31 January to 19 February) for influenza B. The psAVE against influenza B among all ages was $57.5 \%$ in the pooled early phase and $43.4 \%$ in the late phase (Table 2 ). The psAVE against influenza B among those aged 60 and older was $46.2 \%$ in the early phase and $44.5 \%$ in the late phase.

Modelling psAVE against influenza $B$ in the overall season by days since vaccination showed an initial peak, followed by a decline. Among all ages, the psAVE against influenza B increased initially to $70.7 \%$ at day 44. It then declined to $21.4 \%$ at day 207 (Figure 4).

In the early influenza phase, the psAVE against influenza B peaked at $69.9 \%$ at day 39 . It then dipped to $53.7 \%$ at day 99 . The psAVE increased slightly after day 99 to $57.9 \%$ at day 169 .

Among those aged 60 years and older the psAVE against influenza B increased initially to $62.7 \%$ at day 49. It then declined to $4.1 \%$ at day 197 .

\section{Sensitivity analyses}

In the sensitivity analyses with varying location of knots there was almost no difference in model fit (as determined by the $A I C / B I C$ ) and the same aspect of graphs. Varying the number of knots resulted in little difference in model fit. Aspects of the graphs varied slightly with different number of knots, but maintained the general messages in terms of increase and decline. 


\section{FIGURE 6}

Adjusted vaccine effectiveness against influenza $B$, all ages, by season, I-MOVE, influenza seasons (A) 2012/13, (B) $2014 / 15$

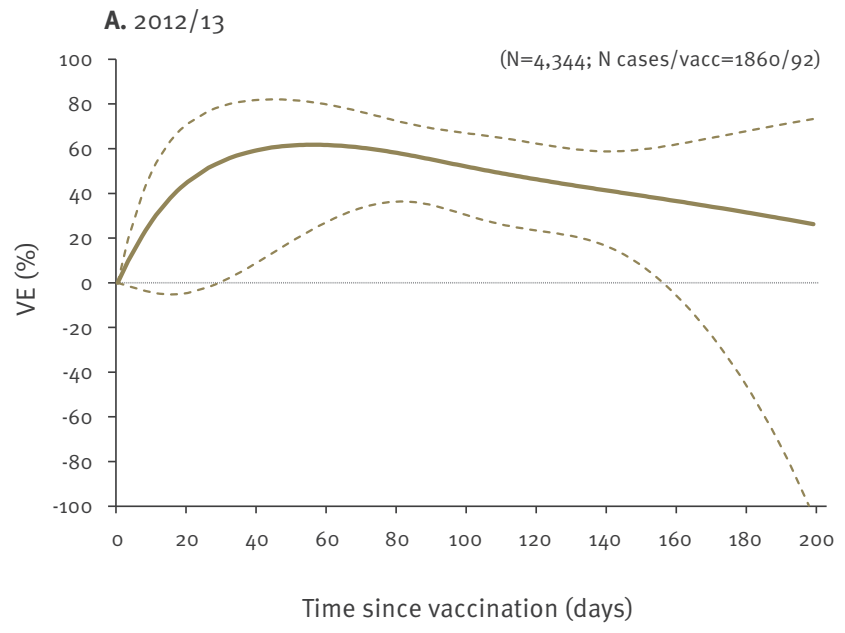

B. $2014 / 15$

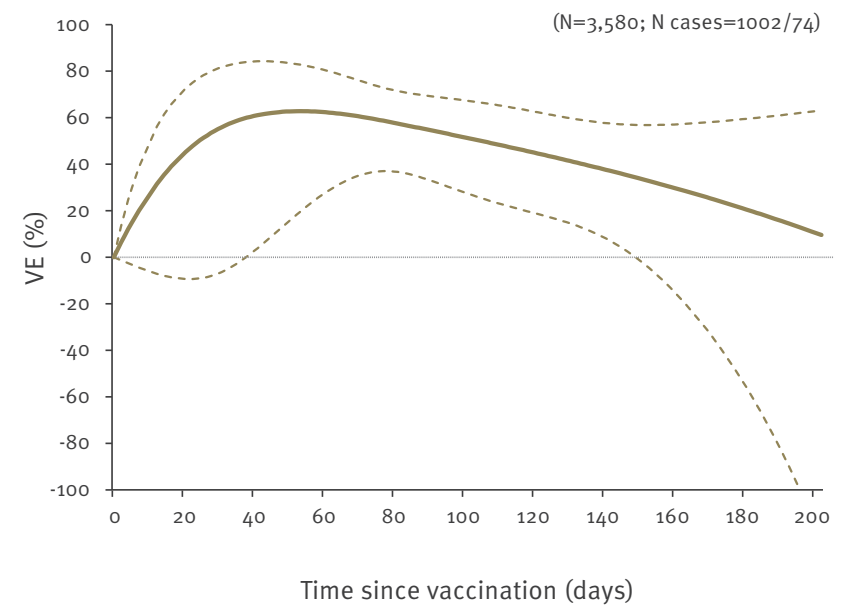

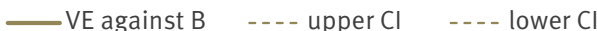

$\mathrm{Cl}$ : confidence intervals; VE: vaccine effectiveness.

We did not find collinearity, as measured by the variance inflation factor, between time since vaccination and onset weeks. The model fit based on both AIC and BIC were substantially better for models including onset weeks, compared with without, for all influenza type/subtypes.

Sample size permitted modelling VE by time since vaccination for some individual seasons: 2011/12, 2013/14 and $2014 / 15$ against influenza $A\left(\mathrm{H}_{3} \mathrm{~N}_{2}\right)$ and 2012/13 and 2014/15 against influenza B. Similar patterns of decline in VE is seen for each individual season as for the pooled seasons (Figures 5-6).

\section{Discussion}

The pooling of our results across influenza seasons suggests a higher VE against influenza $A\left(\mathrm{H}_{3} \mathrm{~N}_{2}\right)$ in the early than in the late phase among all ages and among those aged 60 years and older. This was not observed for influenza $A\left(\mathrm{H}_{1} \mathrm{~N}_{1}\right)$ pdmog and only a small decline in VE was observed against influenza B among all ages.

Modelling VE against influenza $\mathrm{A}\left(\mathrm{H}_{3} \mathrm{~N}_{2}\right)$ by time since vaccination suggested an initial increase in VE up to 30 to 45 days since vaccination, which is in line with other studies [22]. But then the VE declined to less than $0 \%$ among all ages and in those 60 years and older in the overall season, although the upper $\mathrm{Cls}$ remained at about $0 \%$. VE by time since vaccination against influenza B also declined after an initial peak among all ages and those aged over 60 years; however VE never declined to $0 \%$. VE by time since vaccination against influenza $A\left(\mathrm{H}_{1} \mathrm{~N}_{1}\right)$ pdmog among all ages remained stable. VE declined with time since vaccination in the early phase for influenza $\mathrm{A}\left(\mathrm{H}_{3} \mathrm{~N}_{2}\right)$ but not for $\mathrm{A}\left(\mathrm{H}_{1} \mathrm{~N}_{1}\right)$ pdmo9 and $B$.

One limitation of this study is that we were unable to provide VE by time since vaccination against genetic clades of each influenza type/subtype. While there appears to be a waning of vaccine effect over time, we cannot disentangle to what extent this is due to virus change and subsequent non-matching of the vaccine or loss of vaccine-induced immunity within the individual. Information on genetic clade is available in I-MOVE since the $2013 / 14$ season [14]. However, samples selected for sequencing were few and often not representative of the circulating viruses overall. In the 2015/16 season, I-MOVE will pilot a new method for selecting samples for genetic sequencing, using a systematic sampling approach.

Modelling time since vaccination against genetic clade would enable removal of much of the effects of virus change over time from the effects due to waning of vaccine-induced immunity. In this study, we modelled psAVE by time since vaccination restricting to the early phase of the influenza seasons, assuming that virological changes may be fewer in this phase, where we still see a decline in VE against influenza $A\left(\mathrm{H}_{3} \mathrm{~N}_{2}\right)$. The rates and timing of viral mutation during a season are unclear, however it has been suggested that significant amounts of antigenic drift can occur at any time of the season [23]. More information on distribution of genetic clades over time is needed.

We pooled data across seasons to increase sample size and therefore precision. While there was no statistical heterogeneity between season-specific VE estimates, there was some variation, particularly for $\mathrm{A}\left(\mathrm{H}_{3} \mathrm{~N}_{2}\right)$. If there is a true decline in vaccine-induced immunity, then we expect the shape of the seasonal curve to be similar to the curve pooled across seasons, although point estimates along the curve may vary season on season. Single-season models of VE against influenza $A\left(\mathrm{H}_{3} \mathrm{~N}_{2}\right)$ and against influenza $B$ by time since vaccination show similar curves to the pooled-season ones. Sample size did not permit modelling of $\mathrm{VE}$ against $\mathrm{A}\left(\mathrm{H}_{1} \mathrm{~N}_{1}\right)$ pdmo9 by season, nor modelling of $V E$ against $A\left(\mathrm{H}_{3} \mathrm{~N}_{2}\right)$ or $B$ 
Adjusted vaccine effectiveness against influenza A(H3N2), A(H1N1)pdm09 and B, among all ages and those aged 60 years and older, I-MOVE multicentre case-control study, influenza seasons 2010/11-2014/15

\begin{tabular}{|c|c|c|c|c|c|c|c|c|}
\hline \multirow[b]{2}{*}{$\begin{array}{l}\text { Influenza type } \\
\text { / subtype for } \\
\text { analysis }\end{array}$} & \multirow[b]{2}{*}{$\begin{array}{l}\text { Study } \\
\text { year }\end{array}$} & \multirow[b]{2}{*}{$\begin{array}{l}\text { Study sites } \\
\text { included }^{\mathrm{a}}\end{array}$} & \multirow[b]{2}{*}{$\begin{array}{l}\text { Weeks } \\
\text { included in the } \\
\text { analysis }\end{array}$} & \multirow[b]{2}{*}{$\begin{array}{l}\text { Mid-season } \\
\text { date }\end{array}$} & \multicolumn{2}{|c|}{ All ages } & \multicolumn{2}{|c|}{60 years and older } \\
\hline & & & & & $\begin{array}{l}\text { Cases; } \\
\text { vaccinated/ } \\
\text { Controls; } \\
\text { vaccinated }^{\mathrm{b}}\end{array}$ & $\begin{array}{l}\text { Adjusted }{ }^{\mathrm{b}, \mathrm{c}} \\
\text { VE }(95 \% \mathrm{Cl}) \\
\text { all ages }\end{array}$ & $\begin{array}{c}\text { Cases; } \\
\text { vaccinated/ } \\
\text { Controls; } \\
\text { vaccinated }\end{array}$ & $\begin{array}{l}\text { Adjusted }^{\mathrm{d}, \mathrm{e}} \\
\text { VE }(95 \% \mathrm{Cl}) \\
\text { all ages }\end{array}$ \\
\hline \multirow{5}{*}{$A\left(\mathrm{H}_{3} \mathrm{~N}_{2}\right)$} & $2011 / 12$ & $\begin{array}{c}\mathrm{FR}, \mathrm{ES}, \mathrm{HU}, \mathrm{IE}, \mathrm{IT}, \\
\mathrm{PL}, \mathrm{PT}, \mathrm{RO}\end{array}$ & $\begin{array}{c}\text { Wk 46, 2011- } \\
\text { wk 17, } 2012\end{array}$ & 12 Feb 2012 & $\begin{array}{c}1,751 ; 197 / \\
2,125 ; 249 \\
\end{array}$ & $\begin{array}{c}11.3 \\
(-15.6-31.9)\end{array}$ & $\begin{array}{c}251 ; 134 / \\
268 ; 131 \\
\end{array}$ & $\begin{array}{c}14 \cdot 9 \\
(-33 \cdot 4-45.8)\end{array}$ \\
\hline & $2012 / 13$ & $\begin{array}{c}\mathrm{DE}, \mathrm{ES}, \mathrm{FR}, \mathrm{IE}, \mathrm{PL}, \\
\mathrm{PT}, \mathrm{RO}\end{array}$ & $\begin{array}{c}\text { Wk 43, 2012- } \\
\text { wk 16, } 2013\end{array}$ & 4 Feb 2013 & $\begin{array}{c}672 ; 46 / \\
2,340 ; 212 \\
\end{array}$ & $\begin{array}{c}2.2(95 \% \mathrm{Cl}: \\
14.9-60.7) \\
\end{array}$ & $\begin{array}{l}72 ; 22 / \\
190 ; 83 \\
\end{array}$ & $\begin{array}{c}52.8 \\
(5.5-76.5) \\
\end{array}$ \\
\hline & $2013 / 14$ & $\begin{array}{c}\mathrm{DE}, \mathrm{ES}, \mathrm{HU}, \mathrm{IE}, \mathrm{PT}, \\
\mathrm{RO}\end{array}$ & $\begin{array}{c}\text { Wk 47, 2013- } \\
\text { wk 19, } 2014\end{array}$ & 30 Jan 2014 & $\begin{array}{c}614 ; 72 / \\
1,737 ; 208 \\
\end{array}$ & \begin{tabular}{|l|}
$5.9(95 \% \mathrm{Cl}:$ \\
$-35.6-34.7)$ \\
\end{tabular} & $\begin{array}{l}78 ; 38 / \\
183 ; 94 \\
\end{array}$ & $\begin{array}{c}40.7 \\
(-18.0-70.2) \\
\end{array}$ \\
\hline & $2014 / 15$ & $\begin{array}{c}\mathrm{DE}, \mathrm{ES}, \mathrm{HU}, \mathrm{IE}, \mathrm{IT}, \\
\mathrm{PL}, \mathrm{PT}, \mathrm{RO}\end{array}$ & $\begin{array}{c}\text { Wk 47, 2014- } \\
\text { wk 16, } 2015\end{array}$ & 1 Feb 2015 & $\begin{array}{c}1,722 ; 225 / \\
2,547 ; 355\end{array}$ & $\begin{array}{c}14.8 \\
(-5.9-31.4) \\
\end{array}$ & $\begin{array}{c}270 ; 114 / \\
438 ; 199 \\
\end{array}$ & $\begin{array}{c}15.2 \\
(-20.4-40.3)\end{array}$ \\
\hline & Pooled & $\begin{array}{l}\mathrm{DE}, \mathrm{ES}, \mathrm{FR}, \mathrm{HU}, \mathrm{IE} \text {, } \\
\text { IT, PL, PT, RO }\end{array}$ & $\begin{array}{l}\text { All of the } \\
\text { weeks } \\
\text { mentioned } \\
\text { above }\end{array}$ & NA & $\begin{array}{l}4,759 ; 540 / \\
8,979 ; 1040\end{array}$ & $\begin{array}{c}15.0 \\
(2.6-25.8) \\
I^{2}: 27.3 \\
p=0.248\end{array}$ & $\begin{array}{c}672 ; 308 / \\
1103 ; 517\end{array}$ & $\begin{array}{c}23.0 \\
(3.2-38.7) \\
l^{2}=0.0 \% \\
p=0.404\end{array}$ \\
\hline \multirow{5}{*}{$\mathrm{A}\left(\mathrm{H}_{1} \mathrm{~N}_{1}\right) \mathrm{pdmog}$} & $2010 / 11$ & $\begin{array}{c}\text { FR, ES, HU, IE, IT, } \\
\text { PL, PT, RO }\end{array}$ & $\begin{array}{c}\text { Wk 48, 2010- } \\
\text { wk 14, } 2011\end{array}$ & 14 Jan 2011 & $\begin{array}{l}1,139 ; 39 / \\
2,116 ; 227 \\
\end{array}$ & $\begin{array}{c}53.8 \\
(30.3-69.4) \\
\end{array}$ & $\begin{array}{l}50 ; 12 / \\
284 ; 147\end{array}$ & $\begin{array}{c}73.1^{f} \\
(44.7-86.9)\end{array}$ \\
\hline & $2012 / 13$ & $\begin{array}{c}\mathrm{DE}, \mathrm{ES}, \mathrm{FR}, \mathrm{IE}, \mathrm{PL}, \\
\mathrm{PT}, \mathrm{RO}\end{array}$ & $\begin{array}{c}\text { Wk 47, 2012- } \\
\text { wk 16, } 2013\end{array}$ & 03 Feb-2013 & $\begin{array}{c}978 ; 44 / \\
2,218 ; 214 \\
\end{array}$ & $\begin{array}{c}50.3 \\
(28.3-65.6) \\
\end{array}$ & $\begin{array}{l}50 ; 11 / \\
204 ; 90 \\
\end{array}$ & $\begin{array}{c}59.1^{f} \\
(14 \cdot 3-80.5) \\
\end{array}$ \\
\hline & $2013 / 14$ & $\begin{array}{c}\mathrm{DE}, \mathrm{ES}, \mathrm{HU}, \mathrm{IE}, \mathrm{PT}, \\
\mathrm{RO}\end{array}$ & $\begin{array}{c}\text { Wk 50, 2013- } \\
\text { wk 17, } 2014 \\
\end{array}$ & 23 Jan 2014 & $\begin{array}{c}521 ; 34 / \\
1,592 ; 203 \\
\end{array}$ & $\begin{array}{c}47 \cdot 5 \\
(16.4-67) \\
\end{array}$ & $\begin{array}{l}42 ; 15 / \\
184 ; 96 \\
\end{array}$ & $\begin{array}{c}51.8^{f} \\
\left(-0.5^{-76.9)}\right. \\
\end{array}$ \\
\hline & $2014 / 15$ & $\begin{array}{c}\mathrm{DE}, \mathrm{ES}, \mathrm{HU}, \mathrm{IE}, \mathrm{IT}, \\
\mathrm{PL}, \mathrm{PT}, \mathrm{RO}\end{array}$ & $\begin{array}{c}\text { Wk 47, 2014- } \\
\text { wk 16, } 2015 \\
\end{array}$ & 31 Jan 2015 & $\begin{array}{c}514 ; 36 / \\
2,201 ; 299 \\
\end{array}$ & $\begin{array}{c}53.3 \\
(29.6-69.0) \\
\end{array}$ & $\begin{array}{l}59 ; 20 / \\
392 ; 171 \\
\end{array}$ & $\begin{array}{c}22.4^{f} \\
(-44 \cdot 4-58.4) \\
\end{array}$ \\
\hline & Pooled & $\begin{array}{l}\text { DE, ES, FR. HU, IE, } \\
\text { IT, PL, PT, RO }\end{array}$ & $\begin{array}{l}\text { All of the } \\
\text { weeks } \\
\text { mentioned } \\
\text { above }\end{array}$ & NA & $\begin{array}{l}3,152 ; 153 / \\
8,233 ; 953\end{array}$ & $\begin{array}{c}52.2 \\
(41.6-60.9) \\
l^{2}=0.0 \% \\
p=0.975\end{array}$ & $\begin{array}{c}201 ; 58 / \\
1,027 ; 488\end{array}$ & $\begin{array}{c}54.0 \\
(38.5-64.0) \\
l^{2}=39.4 \% \\
p=0.176\end{array}$ \\
\hline \multirow{4}{*}{ B } & $2010 / 11$ & $\begin{array}{c}\text { FR, ES, HU, IE, IT, } \\
\text { PL, PT, RO }\end{array}$ & $\begin{array}{c}\text { Wk 45, 2010- } \\
\text { wk 13, } 2011\end{array}$ & 31 Jan 2011 & $\begin{array}{l}754 ; 32 / \\
2,131 ; 233\end{array}$ & $\begin{array}{c}55.0 \\
(27.4-72.1) \\
\end{array}$ & $\begin{array}{l}49 ; 18 / \\
284 ; 144\end{array}$ & $\begin{array}{c}42.7^{f} \\
(-12.2-70.7) \\
\end{array}$ \\
\hline & $2012 / 13$ & $\begin{array}{c}\mathrm{DE}, \mathrm{ES}, \mathrm{FR}, \mathrm{IE}, \mathrm{PL}, \\
\mathrm{PT}, \mathrm{RO}\end{array}$ & $\begin{array}{c}\text { Wk 47, 2012- } \\
\text { wk 18, } 2013\end{array}$ & 15 Feb 2013 & $\begin{array}{l}1,860 ; 92 / \\
2,484 ; 236 \\
\end{array}$ & $\begin{array}{c}49.3 \\
(32.4-62) \\
\end{array}$ & $\begin{array}{c}131 ; 38 / \\
225 ; 98 \\
\end{array}$ & $\begin{array}{c}39 \cdot 9 \\
(-3 \cdot 4-65) \\
\end{array}$ \\
\hline & $2014 / 15$ & $\begin{array}{c}\mathrm{DE}, \mathrm{ES}, \mathrm{HU}, \mathrm{IE}, \mathrm{IT}, \\
\mathrm{PL}, \mathrm{PT}, \mathrm{RO}\end{array}$ & $\begin{array}{c}\text { Wk 42, 2014- } \\
\text { wk 19, } 2015\end{array}$ & 19 Feb 2015 & $\begin{array}{c}1,002 ; 74 / \\
2578 ; 354 \\
\end{array}$ & $\begin{array}{c}47.6 \\
(28.4-61.7) \\
\end{array}$ & $\begin{array}{l}129 ; 33 / \\
441 ; 195 \\
\end{array}$ & $\begin{array}{c}53.2 \\
(19.1-73) \\
\end{array}$ \\
\hline & Pooled & $\begin{array}{l}\text { DE, ES, FR, HU, IE, } \\
\text { IT, PL, PT, RO }\end{array}$ & $\begin{array}{l}\text { All of the } \\
\text { weeks } \\
\text { mentioned } \\
\text { above }\end{array}$ & NA & $\begin{array}{c}3,617 ; 198 / \\
7,283 ; 830\end{array}$ & $\begin{array}{c}50.7 \\
(40.5-59.2) \\
I^{2}=0.0 \% \\
p=0.872\end{array}$ & $\begin{array}{l}309 ; 89 / \\
965 ; 445\end{array}$ & $\begin{array}{c}45.7 \\
(24.2-61.1) \\
I^{2}=0.0 \% \\
p=0.801\end{array}$ \\
\hline
\end{tabular}

Cl: confidence intervals; NA: not applicable; VE: vaccine effectiveness; wk: week.

a DE: Germany, ES: Spain; FR: France; HU: Hungary; IE: Ireland; IT: Italy; PL: Poland; PT: Portugal; RO: Romania.

${ }^{b}$ Results from complete case analysis. In some analyses, onset weeks dropped from the model, due to only cases/controls in those weeks. Numbers of records therefore dropped: For A(H3N2) 2011/12: 11; 2012/13 45; 2013/14: 20; 2014/15: 222; pooled: 68 For A(H1N1)pdmo9: 2012/13: 53; 2014/15: 205; pooled: 152. For B: 2010/11: 1; 2014/15: 152; pooled: 62 .

c Adjusted by study site, age (as restricted cubic spline for all analyses except 2014/15 against $A\left(\mathrm{H}_{3} \mathrm{~N} 2\right)$ where age group is used), sex, presence of chronic disease and week of symptom onset. For the pooled-season results, VE is additionally adjusted by season. Results may vary to previously published estimates due to different models applied.

${ }^{d}$ Results from complete case analysis. In some analyses, onset weeks/months dropped from the model, due to only cases/controls in those weeks/months: Numbers of records therefore dropped: For A(H3N2) 2011/12: 23; 2012/13 15; 2013/14: 3; 2014/15: 33; pooled: 49. For A(H1N1)pdmo9: 2012/13: 12; 2014/15: 10; pooled: 59. For B: 2012/13: 6; 2014/15: 31; pooled: 22.

e Adjusted by study site, age (as restricted cubic spline), sex, presence of chronic disease and week/month of symptom onset. For the pooledseason results, VE is additionally adjusted by season. Results may vary to previously published estimates due to different models applied.

${ }^{f}$ Crude VE. VE adjusted by study site only

for each season. Even when pooling across seasons, sample size remained limited and we were not able to estimate psAVE against influenza $A\left(\mathrm{H}_{1} \mathrm{~N}_{1}\right)$ pdmog by time since vaccination among those aged 60 and older, nor psAVE by time since vaccination in the early season among those aged 60 and older against any influenza type/subtype. In addition, Cls were wide at the outer limits of time since vaccination, but precision was good between 60 and 120 days among all ages and for all influenza types/subtypes. This corresponds to 2 to 4 months after vaccination campaigns and is generally the period where the main epidemic occurs.

Different vaccines were used not only in the different seasons, but also by country and within regions within countries. Some individuals were vaccinated 
Pooled-season adjusted vaccine effectiveness against influenza A(H3N2), A(H1N1)pdm09 and B, among all ages and those aged 60 years and older, by early/late influenza phase, I-MOVE multicentre case-control study, influenza seasons 2010/11-2014/15

\begin{tabular}{|c|c|c|c|c|}
\hline Influenza type/subtype & Age group & Season ${ }^{a}$ & Cases;vacc/ Controls;vacc ${ }^{b}$ & Adjusted VE $(95 \% \mathrm{Cl})^{\mathrm{b}, \mathrm{c}}$ \\
\hline \multirow{4}{*}{$\mathrm{A}\left(\mathrm{H}_{3} \mathrm{~N}_{2}\right)$} & \multirow{2}{*}{ All ages } & Early pooled & 2,$395 ; 207 / 4,552 ; 490$ & $32.1(16.3-44.9)$ \\
\hline & & Late pooled & 2,$364 ; 333 / 4,427 ; 550$ & $-2.8(-23.5-14.4)$ \\
\hline & \multirow{2}{*}{60 years and older } & Early pooled & $286 ; 109 / 5,17 ; 235$ & $36.8(9.7-55.8)$ \\
\hline & & Late pooled & $386 ; 199 / 585 ; 282$ & $9.2(-23.5-33.3)$ \\
\hline \multirow{4}{*}{ A(H1N1)pdmo9 } & \multirow{2}{*}{ All ages } & Early pooled & 1,$573 ; 69 / 3,243 ; 346$ & $50.1(32.2-63.3)$ \\
\hline & & Late pooled & 1,$579 ; 84 / 4,990 ; 607$ & $52.9(38.5-64.0)$ \\
\hline & \multirow{2}{*}{60 years and older } & Early pooled ${ }^{\mathrm{d}}$ & $86 ; 29$ / 412;186 & $44.7(7.5-67.0)$ \\
\hline & & Late pooled ${ }^{\mathrm{e}}$ & $115 ; 29$ / 674;327 & $61.2(37.7-75.8)$ \\
\hline \multirow{4}{*}{ B } & \multirow{2}{*}{ All ages } & Early pooled & 1,$829 ; 94 / 4,390 ; 499$ & $57.5(43.8-67.8)$ \\
\hline & & Late pooled & 1,$788 ; 104 / 2,893 ; 331$ & $43.4(26.4-56.4)$ \\
\hline & \multirow{2}{*}{60 years and older } & Early pooled $^{f}$ & $166 ; 50 / 584 ; 273$ & $46.2(15.8-65.6)$ \\
\hline & & Late pooled ${ }^{f}$ & $143 ; 39$ / 399;177 & $44.5(8.7-66.3)$ \\
\hline
\end{tabular}

$\mathrm{Cl}$ : confidence intervals; VE: vaccine effectiveness.

a Distinction between early and late season was based on a mid-season date with an equal number of type/subtype-specific cases by dates of onset on either side.

${ }^{b}$ Results from complete case analysis. In some analyses, onset weeks/months dropped from the model, due to only cases/controls in those weeks. Numbers of records therefore dropped: For $\mathrm{A}\left(\mathrm{H}_{3} \mathrm{~N}_{2}\right)$ : all ages early season: 58; all ages late season: 10; 60years and older early season: 38; 60 and olderlate season: 12. For $\mathrm{A}\left(\mathrm{H}_{1} \mathrm{~N}_{1}\right)$ pdmo9: all ages early season: 152. For B: all ages early season: 62 ; 60 years and older early season: 10; 60years and older late season: 1 .

c Adjusted by study site, age (as restricted cubic spline), sex, presence of chronic disease, week of symptom onset and season, unless otherwise specified.

${ }^{d}$ Crude VE. VE adjusted by study site and season only.

e Adjusted by study site, season and onset month only.

${ }^{\mathrm{f}}$ Adjusted as in ${ }^{\mathrm{b}}$, but using onset month, rather than onset week.

with adjuvanted vaccine, which may elicit a different immune response, particularly in relation to duration of protection [24]. While $21 \%$ of vaccinated patients with known vaccination brand received an adjuvanted vaccine, $67 \%$ of these were vaccinated with a vaccine adjuvanted by aluminium gel phosphate, which has been reported to be inferior to emulsion adjuvants in other vaccines [25]. With an increase in sample size, estimates of psAVE by time since vaccination by group of vaccines (split virion, subunit, adjuvanted) could be carried out.

Immune response may differ by age group [26], which is why we estimated psAVE by time since vaccination among those aged 60 and over. PsAVE by time since vaccination was similar in this age group as in all ages. However, a greater sample size is needed to provide more precision, particularly when partitioning by early season. A larger sample size is also needed to provide estimates for other age groups.

In this study there was no change in VE against influenza $A\left(\mathrm{H}_{1} \mathrm{~N}_{1}\right)$ pdmog by time since vaccination. This is in line with a study suggesting protection of monovalent $A\left(H_{1} N_{1}\right)$ vaccination in children and adults that persisted across several seasons [27]. The vaccine component for $A\left(\mathrm{H}_{1} \mathrm{~N}_{1}\right)$ pdmog was the same in all seasons of the study (A/California/7/2009 $\left(\mathrm{H}_{1} \mathrm{~N}_{1}\right)$-like virus), indicating that the virus remained antigenically homogenous across these seasons [28].

VE against influenza B declined slightly with time since vaccination. The decline of VE by time since vaccination in the early influenza season stabilised around day 99 and the decline was less steep than in the overall season. This decline may be due to changes in circulating influenza B lineage towards the end of the season rather than a decline in vaccine-induced immunity. However single-season estimates from the 2014/15 season, where influenza B lineage circulation across the season is known, do not support this hypothesis. In the $2014 / 15$ season, $71.6 \%(746 / 1038)$ of influenza $B$ cases had lineage information available, among which 740 (99.2\%) were B/Yamagata, yet we saw a small decline over time [29].

VE against influenza $\mathrm{A}\left(\mathrm{H}_{3} \mathrm{~N}_{2}\right)$ declined considerably with time since vaccination. It is also known that this subtype undergoes rapid virological change. Our modelling suggests strong decline in AVE with time since vaccination in 2011/12, 2013/14 and 2014/15. During the $2011 / 12$ and $2014 / 15$ seasons, circulating influenza $A\left(\mathrm{H}_{3} \mathrm{~N}_{2}\right)$ viruses showed an imperfect match to the vaccine virus; however, during the 2013/14 season few characterised $\mathrm{A}\left(\mathrm{H}_{3} \mathrm{~N}_{2}\right)$ viruses differed antigenically from the vaccine virus component [30-32]. If the decline in psAVE with time since vaccination is due at 
least in part to waning of vaccine-induced immunity, further research is needed to understand why this is the case for influenza $A\left(\mathrm{H}_{3} \mathrm{~N}_{2}\right)$ in these seasons and $B$, but not for $\mathrm{A}\left(\mathrm{H}_{1} \mathrm{~N}_{1}\right)$ pdmog.

Previous studies have suggested a within-season decline in VE by partitioning time within the season or time since vaccination into categories $[5,6]$. An Australian study reported a decline in VE, but it was sensitive to the cut-off chosen [33]. In this study we modelled time since vaccination as a spline, which provides added value to the categorical approach. It provides information on the change in AVE continuously for each day between vaccination and onset of symptoms. To our knowledge this type of modelling of AVE by time since vaccination has not been carried out in an influenza VE study before.

While more research is needed to address the effects of virological change over the season in the decrease in VE over time, this study suggests that there is some waning of immunity of the influenza $A\left(\mathrm{H}_{3} \mathrm{~N}_{2}\right)$ component of the vaccine and to a certain extent the $B$ component of the vaccine. These findings underline the importance of carrying out influenza VE studies annually using standardised methodology and in numerous sites in order to continually increase our understanding of the variability of influenza VE.

Current season influenza VE has been suggested to vary by prior season influenza vaccine history [34-36]. Our study would benefit from having taken prior season influenza vaccination into account in the analysis, however, sample size for stratification by receipt of previous season vaccination is still small despite the five year pooling. In addition, it remains uncertain how many prior seasons' vaccination needs to be taken into account and cohort studies may be indicated.

A within-season waning of influenza vaccine effect has several important health and policy implications. A late influenza season may mean an increase in influenza burden, including increased hospitalisations and deaths among those vaccinated, within the season. Vaccination strategies would need to be reconsidered, and could include commencing vaccination campaigns later in the year, as is recommended for the 2015/16 influenza season in Spain [37], providing a booster dose of vaccine later in the influenza season or recommending antiviral treatment among vaccinated in an outbreak (for example in a care home) situation. Careful consideration of each strategy is needed, as for example later vaccination campaigns may result in missed opportunities to vaccinate, in case of an early season.

We urge other study teams to measure VE by time since vaccination, and if possible VE against clades - and to pool data to be able to provide results by age group and vaccine type/product. Serological studies are also needed to complement the VE results. More evidence is urgently needed to assess if the time and frequency of vaccination campaigns should be reviewed. Simultaneously resources should be invested in the development of an improved vaccine, to provide higher protection levels for all influenza types/subtypes overall and across each influenza season.

\section{The I-MOVE multicentre case-control team}

The I-MOVE multicentre case-control team, in addition to the 21 authors listed before (except Chris Robertson) consists of, in alphabetical order of countries:

France: Anne Mosnier, GROG/Open Rome, Paris; Germany: Silke Buda and Kerstin Prahm, Department for Infectious Disease Epidemiology, Respiratory Infections Unit Robert Koch Institute, Berlin; Brunhilde Schweiger, Marianne Wedde and Barbara Biere, National Reference Centre for Influenza, Robert Koch Institute, Berlin; Hungary: Annamária Ferenczi, Department of Public Health, Strategic Planning and Epidemiology, Office of the Chief Medical Officer, Budapest; Éva Hercegh, Influenza Virus Laboratory, National Center for Epidemiology, Budapest; Ireland: Coralie Giese, Justyna Rogalska and Javiera Rebollado, EPIET, European Centre for Disease Control and Prevention, Stockholm; HSE-Health Protection Surveillance Centre, Dublin; Italy: Valeria Alfonsi, Maria Rita Castrucci and Simona Puzzeli, Istituto Superiore di Sanità, Rome; Portugal: Ana Rodrigues, Department of Epidemiology, National Institute of Health Dr. Ricardo Jorge, Lisbon; Raquel Guiomar, Inês Costa and Paula Cristóvão, Department of Infectious Diseases,, National Institute of Health Dr. Ricardo Jorge, Lisbon; Romania: Mihaela Lazar, Alina Elena Ivanciuc, Carmen Maria Cherciu, Maria Elena Mihai, Cristina Tecu and Gheorge Necula, "Cantacuzino" National Institute of Research, Bucharest; Spain: Silvia Jiménez-Jorge, National Centre for Epidemiology, Instituto de Salud Carlos III, Madrid; Jesús Castilla, Instituto de Salud Pública de Navarra, Navarra, CIBERESP; Fernando González Carril, Servicio de Salud Pública, Departamento de Salud, Gobierno del País Vasco; Daniel Castrillejo, Servicio de Epidemiología. Consejería de Bienestar Social y Sanidad, Melilla; Francisco Pozo, National Centre for Microbiology, National Influenza Centre - Instituto de Salud Carlos III, Madrid; Jone Altzíbar, Dirección de Salud Pública de Gipuzkoa, Department of Health, Basque Government, San Sebastián-Donostia; Manuel García Cenoz, Public Health Institute of Navarra, Pamplona; José Lozano, Consejería de Sanidad, Dirección General de Salud Pública, Valladolid; Eva Martínez-Ochoa, Department: Servicio de Epidemiología y Prevención Sanitaria. Dirección General de Salud Pública y Consumo de La Rioja, Logroño; Juana Vanrell, Servicio de Epidemiología, Dirección General de Sanidad y Consumo, Illes Ballears, Palma de Mallorca.

\section{Acknowledgements}

We are grateful to ECDC and WHO-EURO and all patients, practitioners and epidemiologists from the study sites who actively participated in the studies between 201011 and 2014-15. Germany: Michael Herzhoff, Unit for Data Management, Department for Infectious Disease Epidemiology, Robert Koch Institute; Spain: S de Mateo and C Delgado, National Centre of Epidemiology; I Casas and P Pérez Breña, National Centre of Microbiology; Manuel García Cenoz, Instituto de Salud Pública de Navarra, Navarra, CIBERESP; Jone M. Altzibar, Subdirección de Salud Pública de Guipuzkoa, País Vasco. CIBERESP; Inmaculada Aspirichaga Gamarra, Subdirección de Salud Pública y Adicciones de Bizkaia; Larraitz Etxebarriarteun Aranzabal, Subdirección de Salud Pública y Adicciones de Araba/Álava); Tomás Vega, Dirección General de Salud Pública e Investigación, 
Desarrollo e Innovación. Consejería de Sanidad de Castilla y León; Carmen Quiñones and Eva Martinez, Servicio de Epidemiología y Prevención Sanitaria, DGSP y Consumo, La Rioja; Jaume Giménez and Juana $M$. Vanrell, Servicio de Epidemiología, Dirección General de Salut Pública, Baleares, CIBERESP; Virtudes Gallardo and Esteban Pérez, Servicio de Epidemiología. Consejería Salud, Junta de Andalucía; Ana Martínez and Núria Torner, Subdirecció General de Vigilància i Resposta a Emergències en Salut Pública, Agència de Salut Pública de Catalunya); Julián M. Ramos and Maria C. Serrano, Subdirección de Epidemiología. Dirección de Salud Pública. Servicio Extremeño de Salud. Junta de Extremadura; France: Isidore Grog (collective name of the Réseau des GROG network); Sylvie van der Werf, Bruno Lina, Martine Valette, Vincent Enouf, Dominique Rousset, National Reference Centre for Influenza virus France North and South; Astrid Vabret, Françoise Stoll Keller, Geneviève Giraudeau, Hervé Fleury, Laurent Andreoletti, Pierre Pothier, associated hospital laboratories; Marion Quesne, Françoise Barat, William Ouadi, coordination team; Hungary: Zsuzsanna Molnár, K Kaszás, M Rózsa, Á Csohán, National Center for Epidemiology; Italy: MC Rota, S Declich, S Puzelli, MR Castrucci, I Donatelli; Portugal: M Barreto, H Rebelo Andrade, LA Santos, Carlos Matias Dias, José Marinho Falcão (retired), Department of Epidemiology, Instituto Nacional de Saúde Dr Ricardo Jorge, Lisbon; Paulo Gonçalves, Patricia Conde and Pedro Pechirra, Department of Infectious Diseases, Instituto Nacional de Saúde Dr Ricardo Jorge, Lisbon; Rede Médicos Sentinela; Associação Portuguesa de Medicina Geral e Familiar (Portuguese association of general practitioners); Romania: Adriana Pistol, Rodica Popescu, V Alexandrescu, C Sbarcea, A Ivanciuc, G Necula, National Centre for Surveillance and Control of Communicable Diseases,; epidemiologists from sentinel Public Health Directorates Camelia Truica, Elena Duca, Suzan Ibram, Dan Decebal, Mariana Ioan, Carmen Sima, Georgeta Marga, Viorica Mihalascu, Carmen Scintei, Cornelia Anghel; Ireland: Aidan O'Hora, Darina O'Flanagan, D Igoe, Suzanne Cotter, A O'Malley, Health Protection Surveillance Centre; Claire Collins and Michael Joyce, Irish College of General Practitioners; Suzie Coughlan, Joanne Moran, G Tuite, A Waters, M Duffy, National Virus Reference Laboratory; Poland: M. Lipke, L Brydak, A.W.Kosek; ECDC: Kari Johansen, Pasi Pettinen, Bruno Ciancio, Angus Nicoll; WHO-EURO, Pernille Jorgensen; EpiConcept: Valérie Nancy, Nathalie Colombo, Guillaume Jeannerod.

\section{Conflict of interest}

None declared

\section{Authors' contributions}

EpiConcept: Esther Kissling undertook the statistical analysis on which the research article is based and led the writing of the article. Marta Valenciano coordinated the I-MOVE multicentre case-control study network. All authors provided contribution to the research article and approved the final version. Alain Moren contributed towards the analysis plan. Alain Moren and Marta Valenciano, were involved in the original methodological design of the I-MOVE multicentre case-control study. In general: Baltazar Nunes and Chris Robertson contributed significantly towards the analysis plan and validation of the modelling. Alain Moren, Marta Valenciano, Esther Kissling, Baltazar Nunes, Udo Buchholz, Amparo Larrauri, Jean Marie Cohen, Beatrix Oroszi, Caterina Rizzo, Ausenda Machado, Daniela Pitigoi, Lisa Domegan, Iwona Paradowska-Stankiewicz, Annicka Reuss, Isabelle Daviaud, Krisztina Horváth, Antonino Bella, Emilia Lupulescu and Joan O'Donnell, have all had a role in modification of this design over the years. All authors read, contributed and approved the manuscript final version. Germany: Annicka Reuss and Udo Buchholz were responsible for validation of data and interpretation of results in the German study site. Spain: Amparo Larrauri, Alin Gherasim and Silvia JiménezJorge were responsible for the study design and coordination of the Spanish study site and the national database. Jesús Castilla, Fernando González Carril and Daniel Castrillejo were involved in the collection and collation of the data. Francisco Pozo undertook the genetic characterization of the influenza strains. All authors contributed to the interpretation of the results and final review of the paper. France: Jean Marie Cohen, Anne Mosnier and Isabelle Daviaud participated in the coordination of the French study site and management of the French database. Portugal: Baltazar Nunes and Ausenda Machado were responsible for the study design in Portugal study site. Ireland: Lisa Domegan and Joan O'Donnell were responsible for the study design and coordination of the Irish study site. Romania: Daniela Pitigoi coordinated epidemiological side of the Romanian study site. Daniela Pitigoi was responsible for the study design in Romanian study site. Daniela Pitigoi collected data and enrolled patients. Emilia Lupulescu coordinated the laboratory side of the study. Poland: Iwona Paradowska-Stankiewicz and Monika Korczyńska were responsible for the study design and coordination in the Polish study site.

\section{References}

1. VENICE III Consortium. National seasonal influenza vaccination survey for 2012-13 influenza season in EU/EEA. November 2013-June 2014. Available from: http://venice.cineca.org/ VENICE_Seasonal_Influenza_2012-13_v10.pdf

2. Kissling E, Valenciano M, Cohen JM, Oroszi B, Barret A-S, Rizzo C, et al. I-MOVE multi-centre case control study 2010-11: overall and stratified estimates of influenza vaccine effectiveness in Europe. PLoS One. 2011;6(11):e27622. DOI: 10.1371/journal.pone.0027622 PMID: 22110695

3. Skowronski DM, Tweed SA, De Serres G. Rapid decline of influenza vaccine-induced antibody in the elderly: is it real, or is it relevant?] Infect Dis. 2008;197(4):490-502. DOI: 10.1086/524146 PMID: 18275271

4. Kissling E, Valenciano M, Larrauri A, Oroszi B, Cohen JM, Nunes $B$, et al. Low and decreasing vaccine effectiveness against influenza $\mathrm{A}\left(\mathrm{H}_{3}\right)$ in 2011/12 among vaccination target groups in Europe: results from the I-MOVE multicentre casecontrol study. Euro Surveill. 2013;18(5):20390.PMID: 23399425

5. Pebody R, Andrews N, McMenamin J, Durnall H, Ellis J, Thompson $\mathrm{Cl}$, et al. Vaccine effectiveness of 2011/12 trivalent seasonal influenza vaccine in preventing laboratoryconfirmed influenza in primary care in the United Kingdom: evidence of waning intra-seasonal protection. Euro Surveill. 2013;18(5):20389.PMID: 23399424

6. Castilla J, Martínez-Baz I, Martínez-Artola V, Reina G, Pozo F, García Cenoz M, et al. , Primary Health Care Sentinel Network, Network for Influenza Surveillance in Hospitals of Navarre. Decline in influenza vaccine effectiveness with time after vaccination, Navarre, Spain, season 2011/12.Euro Surveill. 2013;18(5):20388.PMID: 23399423

7. Jiménez-Jorge S, de Mateo S, Delgado-Sanz C, Pozo F, Casas I, Garcia-Cenoz M, et al. Spanish Influenza Sentinel Surveillance System. Effectiveness of influenza vaccine against laboratory-confirmed influenza, in the late $2011-2012$ season in Spain, among population targeted for vaccination.BMC Infect Dis. 2013;13(1):441. DOI: 10.1186/1471-2334-13-441 PMID: 24053661

8. Belongia EA, Sundaram ME, McClure DL, Meece JK, Ferdinands J, VanWormer JJ. Waning vaccine protection against influenza $A\left(\mathrm{H}_{3} \mathrm{~N}_{2}\right)$ illness in children and older adults during a single season.Vaccine. 2015;33(1):246-51. DOI: 10.1016/j. vaccine.2014.06.052 PMID: 24962752

9. Chen R, Holmes EC. The evolutionary dynamics of human influenza B virus.J Mol Evol. 2008;66(6):655-63. DOI: 10.1007/ so0239-008-9119-z PMID: 18504518

10. Bedford T, Suchard MA, Lemey P, Dudas G, Gregory V, Hay AJ, et al. Integrating influenza antigenic dynamics with molecular evolution. eLife. 2014;3:e01914. DOI: 10.7554/eLife.01914 PMID: 24497547

11. Ohmit SE, Petrie JG, Cross RT, Johnson E, Monto AS. Influenza hemagglutination-inhibition antibody titer as a correlate of vaccine-induced protection.J Infect Dis. 2011;204(12):1879-85. DOI: 10.1093/infdis/jir661 PMID: 21998477

12. Trombetta CM, Perini D, Mather S, Temperton N, Montomoli E. Overview of Serological Techniques for Influenza Vaccine 
Evaluation: Past, Present and Future.Vaccines (Basel). 2014;2(4):707-34. DOI: 10.3390/vaccines2040707 PMID: 26344888

13. Kissling E, Valenciano M, Buchholz U, Larrauri A, Cohen JM, Nunes B, et al. Influenza vaccine effectiveness estimates in Europe in a season with three influenza type/subtypes circulating: the I-MOVE multicentre case-control study, influenza season 2012/13. Euro Surveill. 2014;19(6):20701. DOI: $10.2807 / 1560-7917 . E S 2014 \cdot 19 \cdot 6.20701$ PMID: 24556348

14. Valenciano $M$, Kissling E, Reuss A, Jiménez-Jorge $S$, Horváth JK, Donnell JMO, et al. , I-MOVE Multicentre Case Control Study Team. The European I-MOVE Multicentre 2013-2014 Case-Control Study. Homogeneous moderate influenza vaccine effectiveness against $\mathrm{A}\left(\mathrm{H}_{1} \mathrm{~N}_{1}\right) \mathrm{pdm} 09$ and heterogenous results by country against $\mathrm{A}\left(\mathrm{H}_{3} \mathrm{~N} 2\right)$.Vaccine. 2015;33(24):2813-22. DOI: 10.1016/j.vaccine.2015.04.012 PMID: 25936723

15. Valenciano M, Kissling E, Ciancio BC, Moren A. Study designs for timely estimation of influenza vaccine effectiveness using European sentinel practitioner networks.Vaccine. 2010;28(46):7381-8. DOI: 10.1016/j.vaccine.2010.09.010 PMID: 20851086

16. Valenciano M, Kissling E, Cohen J-M, Oroszi B, Barret A-S, Rizzo C, et al. Estimates of pandemic influenza vaccine effectiveness in Europe, 2009-2010: results of Influenza Monitoring Vaccine Effectiveness in Europe (I-MOVE) multicentre case-control study. PLoS Med. 2011;8(1):e1000388. DOI: 10.1371/journal.pmed.1000388 PMID: 21379316

17. European Centre for Disease Prevention and Control (ECDC). Protocol for case-control studies to measure influenza vaccine effectiveness in the European Union and European Economic Area Member States. Stockholm: ECDC; 2009. Available from: http://www.ecdc.europa.eu/en/publications/ Publications/o907 TED Influenza $\mathrm{AH}_{1} \mathrm{~N}_{1}$ Measuring Influenza_Vaccine_Effectiveness_Protocol_Case_Control_ Studies.p df

18. European Commission. Commission Decision 2009/363/ EC of 30 April 2009 amending Decision 2002/253/EC laying down case definitions for reporting communicable diseases to the Community network under Decision No 2119/98/EC of the European Parliament and of the Council. 2009 Jan p. 58. Report No.: OJ L 110. Available from: http://eur-lex.europa.eu/ LexUriServ/LexUriServ.do?uri=0J:L:2009:110:0058:0059:EN:P DF

19. Huedo-Medina TB, Sánchez-Meca J, Marín-Martínez F, Botella J. Assessing heterogeneity in meta-analysis: Q statistic or I2 index?Psychol Methods. 2006;11(2):193-206. DOI: 10.1037/1082-989X.11.2.193 PMID: 16784338

20. Harrell FE. Regression modeling strategies: with applications to linear models, logistic regression, and survival analysis. New York: Springer; 2001. 568 p.

21. Guess HA. Exposure-time-varying hazard function ratios in case-control studies of drug effects.Pharmacoepidemiol Drug Saf. 2006;15(2):81-92. DOI: 10.1002/pds.1164 PMID: 16287211

22. Nichol K, Nicholson K, Webster RG, Hay AJ. Efficacy/clinical effectiveness of inactivated influenza virus vaccines in adults. Textbook of influenza. Blackwell Science; 1998.

23. Boni MF, Gog JR, Andreasen V, Feldman MW. Epidemic dynamics and antigenic evolution in a single season of influenza A.Proc Biol Sci. 2006;273(1592):1307-16. DOI: 10.1098/rspb.2006.3466 PMID: 16777717

24. Hobson D. The potential role of immunological adjuvants in influenza vaccines.Postgrad Med J. 1973;49(569):180-4. DOI: 10.1136/pgmj.49.569.180 PMID: 4802631

25. Traquina P, Morandi M, Contorni M, Van Nest G. MF59 adjuvant enhances the antibody response to recombinant hepatitis B surface antigen vaccine in primates.J Infect Dis. 1996;174(6):1168-75. DOI: 10.1093/infdis/174.6.1168 PMID: 8940205

26. Lambert ND, Ovsyannikova IG, Pankratz VS, Jacobson RM, Poland GA. Understanding the immune response to seasonal influenza vaccination in older adults: a systems biology approach.Expert Rev Vaccines. 2012;11(8):985-94. DOI: 10.1586/erv.12.61 PMID: 23002979

27. Foy HM, Cooney MK, McMahan R. A Hong Kong influenza immunity three years after immunization.JAMA. 1973;226(7):758-61. DOI: 10.1001/jama.1973.03230070024006 PMID: 4800628

28. World Health Organisation (WHO). WHO recommendations on the composition of influenza virus vaccines [Accessed on 22 Oct 2015]. Available from: http://www.who.int/influenza/ vaccines/virus/recommendations/en/

29. Valenciano M, Kissling E, Reuss A, Rizzo C, Gherasim A, Horváth JK, et al. ,. Vaccine effectiveness in preventing laboratory-confirmed influenza in primary care patients in a season of co-circulation of influenza $A\left(\mathrm{H}_{1} \mathrm{~N}_{1}\right)$ pdmo9, $B$ and drifted $\mathrm{A}\left(\mathrm{H}_{3} \mathrm{~N}_{2}\right)$, I-MOVE Multicentre Case-Control Study, Europe 2014/15. Euro Surveill. 2016;21(7):30139. .

30. European Centre for Disease Prevention and Control (ECDC). Influenza Surveillance in Europe; Season 2011-12. Stockholm: ECDC; 2012.Available from: http://ecdc.europa.eu/en/ publications/Publications/Influenza-Europe-2011-2012surveillance-report.pdf

31. European Centre for Disease Prevention and Control (ECDC). Influenza in Europe - season 2013-14. Stockholm: ECDC; 2014. Available from: http://ecdc.europa.eu/en/publications/ Publications/Influenza-2013-14-season-report.pdf

32. European Centre for Disease Prevention and Control (ECDC). Risk Assessment - Seasonal influenza in the EU/EEA countries 2014/15. Stockholm, ECDC; 2015. Available from: http:/lecdc. europa.eu/en/publications/Publications/seasonal-influenzarisk-assessment.pdf

33. Sullivan SG, Komadina N, Grant K, Jelley L, Papadakis G, Kelly $\mathrm{H}$. Influenza vaccine effectiveness during the 2012 influenza season in Victoria, Australia: influences of waning immunity and vaccine match.J Med Virol. 2014;86(6):1017-25. DOI: 10.1002/jmv.23847 PMID: 24395730

34. Ohmit SE, Petrie JG, Malosh RE, Fry AM, Thompson MG, Monto AS. Influenza vaccine effectiveness in households with children during the 2012-2013 season: assessments of prior vaccination and serologic susceptibility.J Infect Dis. 2015;211(10):1519-28. DOI: 10.1093/infdis/jiu650 PMID: 25416812

35. Skowronski DM, Chambers C, Sabaiduc S, De Serres G, Dickinson JA, Winter AL, et al. Interim estimates of 2014/15 vaccine effectiveness against influenza $A\left(\mathrm{H}_{3} \mathrm{~N}_{2}\right)$ from Canada's Sentinel Physician Surveillance Network, January 2015. Euro Surveill. 2015;20(4):21022. DOI: 10.2807/1560-7917. ES2015.20.4.21022 PMID: 25655053

36. MCLean HQ, Thompson MG, Sundaram ME, Meece JK, McClure $\mathrm{DL}$, Friedrich TC, et al. Impact of repeated vaccination on vaccine effectiveness against influenza $A\left(\mathrm{H}_{3} \mathrm{~N}_{2}\right)$ and $B$ during 8 seasons. Clin Infect Dis. 2014;59(10):1375-85. DOI: 10.1093/cid/ ciu680 PMID: 25270645

37. Consejo interterritorial, Sistema Nacional de Salud. Recomendaciones de vacunacion frente a la gripe, Temporada 2015-2016. 9 Sep 2015 [Accessed on 24 Nov 2015]. Available from: http://www.msssi.gob.es/profesionales/saludPublica/ prevPromocion/vacunaciones/docs/Recomendaciones_ vacunacion_gripe2015_2016.pdf

\section{License and copyright}

This is an open-access article distributed under the terms of the Creative Commons Attribution (CC BY 4.0) Licence. You may share and adapt the material, but must give appropriate credit to the source, provide a link to the licence, and indicate if changes were made.

This article is copyright of the authors, 2016. 